\title{
Progress in antiretroviral drug delivery using nanotechnology
}

This article was published in the following Dove Press journal:

International Journal of Nanomedicine

21 July 2010

Number of times this article has been viewed

\section{Rama Mallipeddi \\ Lisa Cencia Rohan}

University of Pittsburgh, Department of Pharmaceutical Sciences, School of Pharmacy, Magee Womens Research Institute, Pittsburgh, PA, USA
Correspondence: Lisa Cencia Rohan University of Pittsburgh, Magee Womens Research Institute, 204 Craft Avenue, Pittsburgh, PA 15213, USA

$\mathrm{Tel}+141264 \mid 6108$

Fax + 1 4I2 64I 6170

Email rohanlc@upmc.edu
Abstract: There are currently a number of antiretroviral drugs that have been approved by the Food and Drug Administration for use in the treatment of human immunodeficiency virus (HIV). More recently, antiretrovirals are being evaluated in the clinic for prevention of HIV infection. Due to the challenging nature of treatment and prevention of this disease, the use of nanocarriers to achieve more efficient delivery of antiretroviral drugs has been studied. Various forms of nanocarriers, such as nanoparticles (polymeric, inorganic, and solid lipid), liposomes, polymeric micelles, dendrimers, cyclodextrins, and cell-based nanoformulations have been studied for delivery of drugs intended for HIV prevention or therapy. The aim of this review is to provide a summary of the application of nanocarrier systems to the delivery of anti-HIV drugs, specifically antiretrovirals. For anti-HIV drugs to be effective, adequate distribution to specific sites in the body must be achieved, and effective drug concentrations must be maintained at those sites for the required period of time. Nanocarriers provide a means to overcome cellular and anatomical barriers to drug delivery. Their application in the area of HIV prevention and therapy may lead to the development of more effective drug products for combating this pandemic disease.

Keywords: drug delivery, HIV, antiretrovirals, nanoparticles, liposomes, dendrimers

\section{Introduction}

Human retroviruses are of four major types, ie, human $\mathrm{T}$ cell leukemia viruses, HTLV-1, HTLV-2, and human immunodeficiency viruses, HIV-1 and HIV-2. HTLV-1 and HTLV-2 belong to the subclass of oncovirinae and cause adult $\mathrm{T}$ cell leukemia and spastic paraparesis. HIV-1 and HIV-2 from the subclass lentivirinae are responsible for causing acquired immunodeficiency syndrome (AIDS). All of these viruses infect CD4 receptor-bearing T cells. HIV-1 is the most pathogenic virus of these four types, and is mainly responsible for the global AIDS pandemic. HIV infection is spread by the transfer of body fluids due to blood transfusion, organ transplant, sexual contact, or perinatally from mother to offspring. Currently, more than 33 million people are HIV-positive, substantiating the pathogenesis of this disease. ${ }^{1}$ Over the past 25 years, there has been an extensive amount of research conducted to understand the pathogenesis of the infection and for the development of prevention methods and treatment strategies.

Sexual transmission of HIV occurs at the mucosal surface. The female genital tract is the primary route of heterosexual HIV transmission. ${ }^{2,3}$ Sexual transmission of HIV by the rectal route is also a major problem, given that the physiology of the rectum makes it more susceptible to infection. ${ }^{4}$ Immune cells, ie, T cells, macrophages, and 
dendritic cells are the primary targets for HIV infection. In females, these are present in the subepithelial layers of the vaginal and cervical mucosa. ${ }^{5}$ HIV transmitted during sexual intercourse by semen or other biological fluids penetrates the stratified squamous epithelium of the vagina and the ectocervix or the columnar epithelium of the endocervix to infect the target cells. Several mechanisms have been proposed for the in vivo transmission of HIV, including direct infection of the epithelial cells, transcytosis through the epithelial cells, epithelial transmigration, uptake by intraepithelial Langerhans cells, and migration through physical breaches in the epithelium. ${ }^{6,7}$ However, the mechanisms involved in the sexual transmission of HIV have yet to be fully elucidated.

HIV primarily infects cells of the immune system and central nervous system (CNS). The first step in the infection cycle of HIV is fusion of the viral envelope with the target cell and subsequent release of its genome into the cell. Sequential interactions of the HIV envelope glycoproteins, gp120 and gp41, with CD4 receptors, followed by interactions with CCR5 or CXCR4 coreceptors, initiate HIV target cell fusion. ${ }^{8}$ Several studies have been reported suggesting an alternative endocytotic mechanism of HIV entry. Fusion of HIV with endosomes and micropinosomes has been observed by electron microscopy. ${ }^{9,10}$ Augmentation of HIV infection by blocking endosomal acidification ${ }^{11}$ and its reduction by inhibition of clathrin-mediated endocytosis ${ }^{12}$ support the existence of an endocytotic mechanism of HIV entry. Recently, Miyauchi et al reported the occurrence of complete HIV-1 fusion with cells in the endosomes of the epithelial and lymphoid cells via dynamin-dependent mechanisms. ${ }^{13}$ According to these studies, HIV enters cells via endocytosis at the cell membrane. Subsequently, the infectious HIV fuses with an endosome but not with the plasma membrane. Once fusion of the HIV membrane with the host cell occurs, the viral RNA genome is released into the cell where it undergoes reverse transcription followed by integration of the proviral DNA into the host chromosome. Subsequent to translation, immature viral particles egress the cell by assembly of the viral proteins at the cell membrane. Structural rearrangement subsequent to virion budding generates a mature virus that can infect other cells.

Antiretroviral drugs for the treatment of retroviral infections, primarily HIV, are of different categories based on the stage of the HIV life cycle that they act on. Reverse transcriptase inhibitors act by blocking the activity of the reverse transcriptase enzyme, thus preventing the construction of viral DNA. Nucleoside analog reverse transcriptase inhibitors, including zidovudine, lamivudine, stavudine, abacavir, emtricitabine, zalcitabine, dideoxycytidine, dideoxynosine, tinofovir disoproxil fumarate, and didanosine act by incorporation into the viral DNA leading to chain termination, whereas nonnucleoside analog reverse transcriptase inhibitors, including etravirine, delavirdine, efavirenz, and nevirapine block the binding potential of the reverse transcriptase enzyme. Protease inhibitors including ritonavir, saquinavir, lopinavir, indinavir, amprenavir, fosamprenavir, darunavir, atazanavir, nelfinavir, and tipranavir interfere with viral assembly by blocking the protease enzyme necessary for cleaving the nascent viral proteins for final assembly into new virions. Fusion inhibitors (enfuvirtide) block the fusion of the virus with the cell membrane and subsequent entry into the host cells. Integrase inhibitors (raltegravir) block the integration of viral DNA into the host cell DNA. Entry inhibitors (maraviroc) bind to CCR5, a coreceptor on the viral membrane surface used in the entry of the virus into the host cell.

Antiretroviral therapy (ART) using any single class of drugs has not been efficient in controlling infection and disease progression due to the development of resistant strains of the virus. Hence, three or more drugs are used in combination, known as highly effective antiretroviral therapy (HAART), to minimize the development of resistant strains by attacking the viral infection more aggressively. HAART has been able to reduce the mortality due to HIV infection significantly and increase the life expectancy of infected individuals. ${ }^{14}$ The median survival of HIV-positive patients has been increased from less than a year to about 10 years due to HAART. ${ }^{15}$ However, HAART has not been a complete solution to the problem. Disease management is challenging due to several factors, such as development of multiple resistant strains, presence of viral reservoir sites that are inaccessible to the existing drug delivery methods, latent cells with integrated HIV DNA which are susceptible to in vivo activation at a later stage, reduced patient compliance due to increased side effects, and toxicity as a result of the high and frequent dosing involved. The high cost associated with HAART is also an important issue, especially in developing nations where HIV prevalence is high. ${ }^{15}$

Propagation of the HIV virus occurs at the cellular and molecular level and is regulated by several enzymes and biochemical processes. Hence, for anti-HIV drugs to be more effective, adequate extra- and intracellular distribution is necessary for sufficient duration of action at the target sites. From a drug delivery standpoint, focus areas can be categorized as ART for prevention of infection (as in sexual transmission), ART for eradicating the virus from the circulation, and ART for removal of the virus from the sanctuary sites. 
Antiretroviral agents that disrupt the viral membrane before attachment of the virus to the host cell can be delivered to the vaginal/rectal lumen without deeper penetration into the mucosa. Once the viral membrane is destroyed, the viral genome of the virus loses its infectivity. Such delivery systems may aid in the prevention of infection. Drug delivery systems that can deliver antiretrovirals to the subepithelial layers, as well as penetrate the target cells to release their drug intracellularly, may help in eradication of the virus from infected cells and prevent further infection. These are preferable because they improve the efficacy of the antiretrovirals by ensuring sufficiently high drug concentrations at the target site of action. Delivery systems that can deliver and maintain therapeutic concentrations of the drug in the systemic circulation are useful to reduce and/or eliminate the viral load and treat HIV infection. Targeted delivery systems that can cross the physiological barriers and deliver their payload to the viral sanctuary sites, such as the CNS, lymphatic system, and macrophages intracellularly are useful in eradicating the virus and treatment of HIV infection.

The reservoir sites for HIV are categorized as cellular and anatomical sites, based on the impediments to eliminating the viruses. ${ }^{16} \mathrm{CD} 4+\mathrm{T}$ lymphocytes, macrophages, and follicular dendritic cells constitute cellular reservoirs because the virus exists in a physical state capable of surviving for prolonged periods despite otherwise therapeutic levels of antiretroviral agents. ${ }^{16}$ These sites are not very accessible to antiretroviral drugs per se due to the presence of efflux proteins such as P-glycoprotein and multidrug resistance protein on the cell surface preventing the drugs from attaining therapeutic concentrations intracellularly. The CNS, lymphatic system, lungs, and genital organs constitute anatomical sanctuary sites for the virus, because attaining antiretroviral drug concentrations within the respective anatomic spaces is the limiting factor due to the presence of barriers, such as the blood-brain barrier (BBB), blood-cerebrospinal fluid barrier, and blood-testes barrier. ${ }^{16}$ Drug delivery systems that can deliver therapeutic concentrations of antiretroviral drugs preferentially to these viral sanctuary sites are being investigated to overcome the problems mentioned.

Nanocarriers provide an option for the optimization of drug delivery to the target sites in the body. They can potentially be engineered to deliver antiretroviral drugs preferentially to target sites, with limited or poor distribution to the nontarget sites. The resulting alteration in pharmacokinetics and biodistribution of the antiretrovirals may increase their efficacy and reduce the toxicity both during prevention and treatment of infection.

\section{Nanocarrier drug delivery systems}

Nanocarriers constitute a versatile drug delivery system, due to their ability to overcome physiologic barriers and guide the drug to specific cells or intracellular compartments either by passive or ligand-mediated targeting mechanisms. This is due to their small size, typically in the $10-1000 \mathrm{~nm}$ range. Entry of nanocarriers into the cells can occur via energy-dependent or -independent mechanisms, such as endocytosis, pinocytosis, fluid-phase diffusion, receptor-mediated transport, or facilitated transport. ${ }^{17}$ Endocytosis and receptor-mediated transport are the primary mechanisms of intracellular uptake of nanocarriers. ${ }^{18}$ Nanocarriers can be classified according to the material used for their manufacture, such as liposomes, dendrimers, polymeric nanoparticles, solid lipid nanoparticles, and metal nanoparticles. They are also classified as nanospheres, nanocapsules, or nanoparticles based upon the dispersion of drug within the nanocarrier.

Nanocarriers offer several advantages, such as the protection of drugs against degradation, ${ }^{17,19}$ targeting of drugs to specific sites of action, ${ }^{20,21}$ and delivery of biologic molecules, such as proteins, ${ }^{22}$ peptides, ${ }^{23}$ and oligonucleotides. ${ }^{24,25}$ Nanocarriers are currently being investigated for many therapeutic applications to overcome typical drug delivery challenges, such as conformational stability, physicochemical stability, ${ }^{21}$ enhanced cellular uptake of poorly permeable drugs, ${ }^{21,26}$ reduced cellular and tissue clearance of drugs, ${ }^{21}$ sustained drug delivery, ${ }^{27}$ and reduction of immunogenic response. ${ }^{17}$ The therapeutic efficacy and safety of drugs can be significantly improved by targeted delivery using nanocarriers. A target site may have several specific attributes that can be targeted by either single or multicomponent targeting moieties. Ligands such as transferrin, thiamine, and cell-penetrating peptides, such as HIV-1 transactivating transcriptional activator peptide, are some of the most common targeting moieties used to overcome the CNS barriers to drug delivery. The use of multiple targeting moieties in a nanocarrier system may improve their efficiency in terms of site specificity ${ }^{28}$ However, incorporation of multiple targeting moieties into a single nanocarrier increases the complexity of the formulation processing required, which may result in lower yield, higher production cost, and scale-up difficulties.

The small size of the nanocarriers enables them to be transported more easily through barriers, such as mucus and mucosal epithelium, by passive or active transport mechanisms. ${ }^{18}$ It is their size that allows them to penetrate through cells and deliver drugs intracellularly without risking extracellular degradation. However, the smaller the size of the nanocarrier, the harder it is to control the drug release 
kinetics from the nanocarrier. Drug diffuses out of smaller nanocarriers faster, resulting in burst effects and an inability to obtain sustained or controlled drug delivery over prolonged periods of time. ${ }^{29,30}$ The drug release kinetics can be improved by increasing the size of the nanocarriers, which results in higher drug loading and prolonged drug release with a lower burst effect. ${ }^{31,32}$ However, increasing nanocarrier size may lead to their hindered transport across membranes. Optimization of particle size with desired release characteristics is a challenge with nanocarrier drug delivery systems.

There are several additional challenges with respect to nanocarrier formulations. Due to the small size of nanocarriers, their higher surface area compared with micro- and macrosystems provides a high surface energy which can result in stability issues, such as aggregation. ${ }^{17,33}$ Nanocarriers have an extremely limited drug reservoir volume due to their high surface to volume ratios. In addition, the conventionally low entrapment efficiencies obtained for nanocarriers reduces the amount of drug that can actually be loaded..$^{29}$ A significant amount of drug may also be lost during loading due to the nature of the processes involved in nanocarrier production.

Nevertheless, the benefits associated with nanocarriers for antiretroviral drug delivery far outweigh their challenges. A significant amount of research has been conducted to overcome the challenges associated with nanocarriermediated drug delivery with varying degrees of success. Although several reviews are available on this topic, ${ }^{15,21,34-39}$ this review provides a cumulative overview of the many different applications of nanotechnologies specific to their use for delivery of antiretroviral drugs in HIV prevention and therapy. Different types and modifications of nanocarriers have been studied for improved delivery of antiretroviral drugs. These are discussed in the following sections.

\section{Nanotechnology for antiretroviral drug delivery Polymeric nanoparticles}

Synthetic and semisynthetic polymers have attracted great attention for nanotechnology-based drug delivery due to several desirable features, including manufacturing reproducibility, stability, and sustained drug release. Different materials have been employed in the preparation of nanoparticles, and material choice in some cases is driven by application. Synthetic or semisynthetic polymers, such as poly(lactic acid) (PLA), poly(lactic-co-glycolic acid) (PLGA), poly(alkyl)cynoacrylates, poly(ethylene glycol-co-(lactic-glycolic acid)), poly(caprolactone), and poly(methyl) methacrylate, are frequently used for the manufacture of nanoparticles intended for drug delivery. Of these, PLA and PLGA have been approved for human use by the Food and Drug Administration (FDA). A wide range of drugs of different hydrophilicity or hydrophobicity can be incorporated into these polymers, and their release characteristics can be tailored to meet dosing requirements. The performance of the polymer can be adapted to the intended application by controlling the molecular weight or copolymer composition which influences properties such as degradation rate, thermal sensitivity, and $\mathrm{pH}$ sensitivity. These polymers have the capability to sustain drug release for several weeks. Drug loading is generally achieved by encapsulation, entrapment, or dissolution/dispersion. The biodegradable and biocompatible properties of polymeric nanoparticles make them very attractive candidates for drug delivery, tissue engineering, and biomedical applications.

There have been numerous studies over the past 18 years evaluating the use of various polymeric nanoparticles for the delivery of antiretrovirals. Antiretroviral drugs whose mechanism of action requires that the drug reach target cells must cross the mucosal epithelial barrier to exert their effect when administered by noninvasive routes such as oral, vaginal, or rectal delivery. Nanoparticles provide one strategy to traverse this mucosal barrier. In a study conducted by Ham et al, PLGA nanoparticles were used for vaginal delivery of PSC-RANTES, a CCR5 chemokine receptor inhibitor. ${ }^{22}$ In these studies, PSC-RANTES was encapsulated into PLGA nanoparticles via a double-emulsion, solvent-evaporation method. The nanoparticle system was produced to protect the active agent from the vaginal environment, and facilitate drug penetration into the vaginal and ectocervical tissue, allowing the drug to reach HIV target cells. The uptake of encapsulated PSC-RANTES by excised human ectocervical tissue as evaluated in an ex vivo model was 4.8 times greater than nonencapsulated PSC-RANTES during a four-hour exposure time. Another application of this type of nanocarrier was demonstrated by Dembri et al. ${ }^{40}$ This study involved the preparation of poly(isohexyl cyanate) nanoparticles of zidovudine for the purpose of targeting the lymphoid tissue in the gastrointestinal tract. Use of this carrier system, when compared with aqueous drug solution, resulted in drug levels in the Peyer's patches being four times higher with the encapsulated drug form. In a separate study, Lobenberg et al formulated polyhexylcyanoacrylate nanoparticles for the delivery of zidovudine. ${ }^{41}$ In vivo studies in rodents demonstrated higher zidovudine levels in the body with the encapsulated drug compared with free drug solution after oral administration. However, when oral delivery of the nanoparticles was compared with intravenous 
administration using radioluminography, much of the orally administered nanoparticles were found to remain in the gastrointestinal tract.

Mucus, a dynamic layer present on the surface of the mucosal epithelium, is a major barrier for the delivery of antiretroviral drugs via noninvasive routes. Antiretroviral drugs must pass through mucus layers that may be up to a few hundred microns thick to reach the underlying epithelium and avoid clearance. ${ }^{42}$ Mucoadhesive nanoparticles can reduce the clearance of antiretroviral drugs from these sites and ensure their prolonged retention, resulting in improved absorption of poorly absorbable drugs. Several polymers, such as poloxamers, pectins, chitosans, polyacrylates, and their derivatives, have been used to impart mucoadhesive properties to the nanoparticles by surface coating. ${ }^{17,43,44}$ In spite of extensive research on mucoadhesive nanoparticles for improving drug targeting to or through mucosal surfaces, several drawbacks limit their applications. The mucus turnover rate, influenced by a variety of factors including mucosal site, physiologic conditions, and presence of irritants affects the residence time of mucoadhesive nanoparticles. ${ }^{17,45}$ The second major limitation is that the mucoadhesive nanoparticles interact with and adhere to mucus and, hence, may be unable to reach the underlying epithelium or subepithelial tissues, making them inefficient as intracellular delivery systems. ${ }^{46}$

Mucus-penetrating nanoparticles seem to be a better option for overcoming the mucosal barriers. Surface properties, such as net charge and hydrophilicity of the nanoparticles, play a crucial role in their ability to penetrate the mucus and reach the underlying epithelium. ${ }^{46}$ Mucus is negatively charged due to the carboxyl and sulfate groups present on the mucin proteoglycans. Mucus has high densities of hydrophobic domains which entrap foreign materials by forming polyvalent, low-affinity, adhesive interactions. ${ }^{47,48}$ These interactions pose a challenge, particularly in the design of polymeric nanoparticles, because most of the polymers used for this purpose are either hydrophobic or have a net charge. Mimicking viral surface properties may provide a way to enhance the diffusion of nanoparticles through mucus. Viruses capable of rapid transport in mucus possess hydrophilic surfaces that are densely coated equally with positive and negative charges, creating a net-neutral shell that minimizes hydrophobic and electrostatic adhesive interactions. ${ }^{46,48}$ Successful engineering of neutral surfaces with such high densities of cationic and anionic charges, as in the case with viral proteins, has not been reported so far. Nanoparticles with hydrophobic groups which were masked from mucus interaction by covalently linked polyethylene glycol (PEG) moieties were designed by Lai et al. ${ }^{49}$ Surface modification improved the transport rates by several orders of magnitude. The nanoparticles with neutral surfaces were transported faster through human mucus compared with unmodified nanoparticles. The rate of transport was found to be dependent on nanoparticle size, density of surface coverage, and PEG molecular weight. Higher surface density and lower molecular weight of PEG resulted in better transport of the nanoparticles through mucus.

Lymphoid tissues such as lymph nodes, spleen, and gut-associated lymphoid tissue constitute major sanctuary sites for HIV. Approximately 99\% of HIV replication occurs in activated and productively infected CD4+ T cells of the blood and lymphoid tissues, primarily the lymph nodes. However, the viral load of lymphoid tissues is greater than the circulating blood, because only $2 \%$ of the lymphocytes are in the circulation at a given time, with the remaining being present in the lymphoid tissues, especially in lymph nodes. ${ }^{38}$ Lymph nodes are the sites of $\mathrm{T}$ cell activation and differentiation. They harbor a large number of $\mathrm{T}$ cells, antigen-presenting dendritic cells, and short-lived monocytes and macrophages. Hence, targeting antiretroviral drugs to the lymphoid tissues might help in better management of the viral infection compared with reduction of systemic viral load. Nanoparticles targeting macrophages and other cells of the mononuclear phagocytic system can be used to deliver antiretroviral drugs to the lymphoid tissues. The focus of the majority of the studies dealing with antiretroviral nanoparticles involves targeting the mononuclear phagocytic system, because these cells are responsible for harboring and dissemination of HIV virus to other anatomic sanctuary sites in the body, including lymph nodes. A host of published studies in this area demonstrate the superior ability of antiretroviral nanoparticles to deliver their payload to macrophages and monocytes in vitro. One example of the work in this area is the PLGA nanoparticles containing multiple antiretroviral drugs (ritonavir, lopinavir, and efavirenz) which were fabricated by Destache et al using a multiple emulsion solvent evaporation technique. ${ }^{50}$ The encapsulated antiretrovirals were detected intracellularly in peripheral blood mononuclear cells in vitro after 28 days. On the contrary, unencapsulated antiretrovirals could not be detected after two days. Lobenberg et al studied the distribution of zidovudine-loaded poly(isohexyl cyanate) nanoparticles in vivo in rats. ${ }^{41}$ These studies revealed that encapsulation resulted in a higher concentration of drug in the cells of the reticuloendothelial system.

Nanoparticle surface modification can alter biodistribution and circulation patterns. Shah and Amiji fabricated poly(epsilon-caprolactone) nanoparticles loaded 
with saquinavir for targeting the phagocytic mononuclear system. ${ }^{51}$ The surface of the nanoparticles was modified with poly(ethylene oxide) to prevent aggregation of the nanoparticles. Intracellular drug concentrations were found to be higher with encapsulated saquinavir compared with free drug solution. However, these studies did not include a performance comparison of the surface-modified versus surface-unmodified nanoparticles. Mainardes et al studied the effect of surface modification in a methodical manner using zidovudine-loaded hydrophobic polylactide (PLA) and surface hydrophilic PEG nanoparticles. ${ }^{52}$ The concentrationdependent effects of PEG, used to modify the PLA nanoparticle surfaces, were studied. According to these studies, the uptake of zidovudine by macrophages and polymorphonuclear leucocytes was higher with unmodified PLA nanoparticles than with PEG-modified PLA nanoparticles. PEG did not prevent the phagocytosis completely, even at higher concentrations, indicating a concentration-dependent steric effect.

The CNS is the most important HIV reservoir site. However this site offers limited access to drugs and drug delivery systems. HIV primarily infects the microglial cells of the brain and causes extensive neuronal damage, particularly in the frontal cortex, ultimately leading to dementia. ${ }^{15}$ Antiretroviral drug transport across the $\mathrm{BBB}$ is essential to decrease or eradicate viral load. The BBB inhibits the transport of antiretroviral drugs to the brain by the presence of tight endothelial cell junctions and efflux transporters such as P-glycoprotein, multidrug resistance protein, and multispecific organic anion transporters. ${ }^{20,35}$ Nanoparticles are a means to overcome this barrier because they can cross the BBB by endocytosis/ phagocytosis and can then release drug intracellularly. Kuo initially reported the loading of stavudine, a nucleoside analog reverse transcriptase inhibitor, into polybutylcyanoacrylate (PBCA) and methylmethacrylate-sulfopropylmethacrylate (MMA-SPM) nanoparticles for brain targeting. ${ }^{53}$ By using an in vitro brain microvascular endothelial cell model, Kuo and Chen further evaluated the effect of size of PBCA and MMA-SPM nanoparticles on the permeability of two reverse transcriptase inhibitors (zidovudine and lamivudine) across the BBB. ${ }^{26}$ The permeability of these drugs across the BBB was found to be inversely proportional to nanoparticle size. The permeability of zidovudine and lamivudine was 8-20-fold higher and 10-18-fold higher, respectively, with PBCA nanoparticles, whereas the MMA-SPM nanoparticles led to a $100 \%$ increase in the BBB permeability of both drugs. In a subsequent report, Kuo and $\mathrm{Su}$ studied the transport of stavudine, delavirdine, and saquinavir across the BBB when delivered as PBCA and MMA-SPM nanoparticles. ${ }^{54}$
The results revealed that the permeability of all three drugs increased about 12-16-fold with PBCA nanoparticles and 3-7-fold with MMA-SPM nanoparticles. In a further extension of their studies on nanoparticles, Kuo and Kuo studied the influence of electromagnetic field on the transport of antiretroviral nanoparticles across the BBB. The permeability of saquinavir-loaded PBCA and MMA-SPM nanoparticles across the BBB was enhanced significantly by the application of an electromagnetic field. Larger frequency, modulation or depth of amplitude modulation, or modulation or deviation of frequency modulation, resulted in greater permeability of the nanoparticles..$^{55}$

\section{Inorganic nanoparticles}

Inorganic materials like gold, silver, iron, titanium, copper, silica, and zinc oxide have been fabricated as nanoparticles for several pharmaceutical applications, including cancer therapeutics, ${ }^{56}$ cellular and biomolecular labels, ${ }^{57}$ and biosensors. ${ }^{58}$ Nanoparticles of noble metals like gold, silver, and platinum have been synthesized using a wide variety of methods such as bioreduction, hard template, and solution phase syntheses. ${ }^{59-61}$ Silver nanoparticles have received considerable attention as antimicrobial agents because they have been shown to be effective as antibacterial ${ }^{62}$ and antiviral ${ }^{63,64}$ agents. Antimicrobial effectiveness was shown for both Gram positive and Gram negative bacteria. ${ }^{62,65}$ Antiviral activity of silver nanoparticles has been demonstrated against several types of viruses, including hepatitis B, herpes simplex virus, respiratory syncytial virus, and monkey pox virus. ${ }^{63,66-68}$ Recently, several studies have demonstrated their antiviral activity against HIV-1 in vitro. ${ }^{64,69,70}$ Silver nanoparticles were shown to be effective against a wide range of HIV-1 strains in vitro, including laboratory strains, clinical isolates, $\mathrm{M}$ and $\mathrm{T}$ tropic strains, and resistant strains. ${ }^{70}$ The therapeutic index of silver nanoparticles was found to be 12 times higher than that of silver ions used as silver nitrate and silver sulfadiazine salts, indicating that higher antiviral efficiency was specific to silver nanoparticles. ${ }^{70}$ Silver nanoparticles act as viral entry inhibitors by binding to gp120 and thus preventing CD4mediated viral membrane fusion to host cells and subsequent infectivity. ${ }^{69,70}$ They are also found to inhibit post-entry stages of HIV- $1,{ }^{70}$ indicating that silver nanoparticles act at multiple stages of the HIV life cycle. This would result in reduced risk for the development of viral resistance to silver nanoparticles. However, the in vivo antiviral activity of silver nanoparticles against HIV-1 has yet to be demonstrated.

Another inorganic nanoparticulate system evaluated for antiretroviral drug delivery consists of gold nanoparticles. 
Bowman et al used small molecule-conjugated gold nanoparticles as anti-HIV agents. ${ }^{71}$ SDC-1721, a fragment of the potent HIV inhibitor TAK-779, was synthesized and conjugated to gold nanoparticles. Free SDC-1721 had no inhibitory activity in HIV infection. However, antiretroviral activity comparable with TAK-779 was observed when SDC1721 was conjugated to gold nanoparticles. Gold nanoparticles transformed the biologically inactive SDC-1721 into a multivalent conjugate that effectively inhibited HIV-1 fusion to human T lymphocytes.

One drawback to the use of inorganic nanoparticles is potential toxicity. Toxicity of inorganic nanoparticles must be studied carefully before they can be clinically applied. Several studies have demonstrated the cytotoxic effects of these inorganic nanoparticles. ${ }^{72-75}$ In studies evaluating acute toxicity, silver nanoparticles were found to be highly cytotoxic to mammalian cells based on the assessment of mitochondrial function, membrane leakage of lactate dehydrogenase, and abnormal cell morphologies. ${ }^{72,75}$ Toxicity studies conducted on human lung fibroblast cells (IMR-90) and human glioblastoma cells (U 251) revealed the generation of reactive oxygen species by cells exposed to silver nanoparticles. ${ }^{73}$ DNA damage and cell cycle arrest in the $\mathrm{G}(2)$ or $\mathrm{M}$ phase was observed. In studies by Kawata et al using HepG2 human hepatoma cells, subacute exposure to silver nanoparticles resulted in abnormal cell morphology and increased cell proliferation possibly due to hormesis, ie, a stimulatory effect exhibited by low levels of potentially toxic agents. ${ }^{74}$ The incidence of micronuclei formation, indicative of chromosomal aberrations or breakage, was significantly higher in cells exposed to subacute levels of silver nanoparticles. Studies on rodents showed that silver nanoparticles accumulated in various organs including the lungs, kidneys, brain, liver, and testes. ${ }^{76}$ Furthermore, DNA microarray analysis indicated an induction of a large number of genes, particularly, stressassociated genes coding metallothionine and heat shock protein. ${ }^{74}$ Similar studies on other inorganic nanoparticles, including gold and titanium dioxide, have indicated toxicity via DNA damage and cellular apoptosis. ${ }^{77,78}$

\section{Dendrimers}

Dendrimers are a versatile class of regularly-branched macromolecules with unique structural and topologic features. Small size (typically less than $100 \mathrm{~nm}$ ), narrow molecular weight distribution, and relative ease of incorporation of targeting ligands make them attractive candidates for drug delivery. Dendrimers have minimal polydispersity and high functionality. Similar to polymers, they are obtained by attaching several monomeric units, but unlike the conventional polymers, they have a highly branched three-dimensional architecture. Dendrimers are characterized by the presence of three different topologic sites, ie, a polyfunctional core, interior layers, and multivalent surface. ${ }^{36}$ The polyfunctional core, surrounded by extensive branching, has the ability to encapsulate several chemical moieties. Ammonia and ethylene diamine are two examples of core-synthesizing materials. The core may be surrounded by several layers of highly branched repeating units, such as polyethers, porphyrins, polyamidoamines, polyphenyls, and polyamino acids. The properties of the dendrimer are predominantly based on the multivalent surface, which has several functional groups that interact with the external environment. The precise physicochemical properties of dendrimers can be controlled during synthesis by controlling the core groups, the extent of branching, and the nature and/or number of functional groups on the surface. ${ }^{79,80}$ Dendrimers can not only act as carriers of antiretroviral agents, but can also themselves act as antiretrovirals. Dendrimers with inherent antiretroviral activity can be synthesized by incorporating certain functional groups on their surface that can interfere with the binding of the virus to the cell. A diverse array of dendrimers with various patterns of biologic activity can be synthesized by making subtle changes, such as the type of initiator, branching unit type, dendrimer generation, linker, and surfaces. ${ }^{81}$ The inherent antiviral activity of dendrimers has been demonstrated against influenza virus, ${ }^{82}$ respiratory syncytial virus, ${ }^{83}$ and $\mathrm{HIV}^{84}$ in vitro. These dendrimers primarily act by blocking viral fusion to target cells and thus act as entry inhibitors in the early stages of viral infection, although secondary mechanisms of action at later stages of the viral life cycle have been reported..$^{36,81}$

Water-soluble dendrimers can be used as efficient carriers of antiretroviral agents which can be entrapped in the dendrimer architecture. The antiretrovirals or their prodrugs can also be grafted covalently onto the surface of the dendrimers, either alone or in conjunction with other molecules, such as targeting moieties and fluorescent tags. Multivalent dendrimeric systems have been of much interest in the field of antiviral therapy. Dutta et al developed efavirenz-loaded, tuftsin-conjugated poly(propyleneimine) dendrimers for targeted delivery to macrophages. ${ }^{85}$ Tuftsin is a natural macrophage activator tetrapeptide (Thr-Lys-Pro-Arg) which binds specifically to mononuclear phagocytic cells and enhances their phagocytic activity. These multivalent dendrimers showed reduced cytotoxicity compared with nonconjugated poly(propyleneimine) dendrimers in vitro. The free amino 
groups present on poly(propyleneimine) dendrimers are responsible for their cytotoxicity. Conjugation of tuftsin to poly(propyleneimine) dendrimers reduced the cytotoxicity of these dendrimers, possibly by shielding the positive charges and thus preventing their interaction with cell membranes. The tuftsin-conjugated poly(propyleneimine) dendrimers showed enhanced cellular uptake by mononuclear phagocytic cells and greater anti-HIV activity in vitro. The same research group loaded lamivudine into mannose-capped poly(propyleneimine) dendrimers and observed a significant increase in antiretroviral activity, cellular uptake, and reduced cytotoxicity. ${ }^{86}$ The mannose conjugation enabled the targeted delivery of the lamivudine-loaded dendrimers to macrophages containing lectin receptors on their surface. Dendrimers have been used to transfect silencing RNA (siRNA) to reduce HIV infection in vitro. Amino-terminated carbosilane dendrimers were used to protect and transfer siRNA to lymphocytes in vitro. ${ }^{24}$ These dendrimers bind to siRNA via electrostatic interactions and protect it from RNase degradation.

The V3 loop region of viral gp120 interacts with glycolipids, such as galactosylceramide, on the host cell for cell attachment and subsequent cell entry. ${ }^{87,88}$ Anionic polymers and dendrimers through ionic interactions with the V3 loop of gp120 interfere with viral-host cell interactions. ${ }^{89,90}$ One such anionic dendrimer is SPL7013, a poly-L-lysine dendrimer with naphthalene sulfonic acid terminations. It has a divalent benzhydrylamine amide of L-lysine as the core. Efficacy studies with 5\% w/w SPL7013 as an aqueous gel showed that a single intravaginal dose of the formulation protected pig-tailed macaques from intravaginal simianhuman immunodeficiency virus infection. ${ }^{91}$ VivaGel $^{\circledR}$ is an aqueous-based polyacrylic acid gel containing SPL7013 buffered to physiologic $\mathrm{pH}$. VivaGel is the first dendrimerbased drug application that has been submitted to the US FDA as an investigational new drug. ${ }^{92}$ Phase I clinical trials showed no systemic absorption following intravaginal dosing, indicative of the desired retention in the vaginal lumen. The safety profile of VivaGel was comparable with placebo gel, indicating no toxicity. ${ }^{93}$ The antiretroviral activity of sulfated oligosaccharides is very low. ${ }^{94}$ However, sulfated oligosaccharides when attached to a dendrimer show high antiretroviral activity due to cluster effects. ${ }^{95}$ Recently, Han et al have developed oligosaccharide-based polylysine dendrimers with sulfated cellobiose. ${ }^{96}$ These were shown to possess high anti-HIV activity, almost equivalent to dideoxycytidine, and low cytotoxicity.

Multivalent phosphorus-containing catanionic dendrimers with galactosylceramide analogues were developed by
Blanzat et al. ${ }^{97}$ The influence of the multifunctional core, the alkyl chains, and the surface properties of the dendrimers on their stability, cytotoxicity, and antiretroviral properties were reported by the same group in subsequent studies..$^{98,99}$ Galactosylceramide has a high affinity for the V3 loop of the gp120 viral envelope protein of HIV-1, and subsequently prevents viral fusion to the host cell membrane, thus acting as an entry inhibitor. Although the galactosylceramide dendrimers showed good antiretroviral activity, a low therapeutic index associated with cytotoxicity is one of the issues that need to be addressed before these can be considered promising antiretroviral agents.

\section{Solid lipid nanoparticles}

Solid lipid nanoparticles (SLNs) are made of fatty acids that are solid or semisolid at room temperature. Lipids with high melting point such as stearic acid, glyceryl monostearate, cetyl palmitate, and hydrogenated cocoglycerides and emulsifiers, such as phosphatidylcholine, lecithins, polysorbates, poloxamers, bile salts, and fatty acid coesters are used to prepare and stabilize the SLNs, respectively. Sustained drug release and site specificity for drug delivery can be achieved by altering the properties of SLNs, such as their lipid composition, size, and surface charge. SLNs can be manufactured to release drug in response to an external trigger, such as $\mathrm{pH}$ and temperature. This delivery system offers several advantages such as relative ease of production, sterilization, and scale-up, avoidance of the use of organic solvents, low-cost excipients, and biocompatibility. Compared with nanoemulsions which are liquid lipid encapsulations of the drug, SLNs containing the lipid in the solid state impart greater drug stability and better control over drug-release kinetics.

Zidovudine palmitate-loaded SLNs prepared by Heiati et al are the first reported antiretroviral SLNs. ${ }^{100}$ Trilaurin was used as the lipid core in these systems. Dipalmitoyl phosphatidylcholine alone or in combination with dimyristoylphosphatidylglycerol was used as a coating. The resultant SLNs were either neutral or negatively charged. Drug loading was dependent on the outer phospholipid coat, with higher phospholipid content resulting in greater drug incorporation. In a subsequent study by the same group, the surfaces of these SLNs were modified by the attachment of PEG moieties, thus improving the plasma circulation half-life of the drug. ${ }^{101}$

SLNs have been widely used to overcome biological barriers, such as the BBB and blood-cerebrospinal fluid barrier. The use of SLNs for drug delivery to the brain was first proposed by Yang et al and Zara et al independently in the late 1990s in their studies of the pharmacokinetics 
of two anticancer agents, camptothecin and doxorubicin, respectively. ${ }^{102,103}$ Accumulation of the drug in the brain was observed after both oral and systemic administration of drug-loaded SLNs in rats. Since then, several studies were conducted on the ability of SLNs to improve the brain delivery of drugs. Kuo and Su prepared SLNs loaded with stavudine, delavirdine, and saquinavir independently and evaluated their ability to cross the $\mathrm{BBB}$ in vitro using human brain microvascular endothelial cells. ${ }^{54}$ The entrapment efficiency of the drugs followed their lipophilicity, with the more lipophilic saquinavir having the maximum entrapment efficiency, indicating the better suitability of SLNs to more lipophilic drugs. The permeability of the drugs was improved 4-11-fold when incorporated into SLNs. Chattopadhyay et al used SLNs made of stearic acid for delivery to the brain of atazanavir, a highly lipophilic antiviral protease inhibitor. ${ }^{104}$ In this study the SLNs were prepared by a microemulsion technique using Pluronic F68 as an emulsifier. In vitro studies using hCMEC/D3, a human brain microvessel endothelial cell line, showed a higher uptake of the drug when delivered in SLN form, as compared with free atazanavir. Atazanavir is a substrate for the adenosine triphosphate-binding cassette membrane-associated drug efflux transporters, such as P-glycoprotein. The activity of these efflux transporters results in lower intracellular accumulation of atazanavir. The authors hypothesize that SLNs circumvent P-glycoproteinmediated efflux and mask the drug from the membrane bound P-glycoprotein efflux transporter, thus facilitating its intracellular accumulation.

Several surface modifications were studied to improve the targeting ability of SLNs further. PEG moieties attached to the surface of SLNs impart stealth characteristics to the SLNs and improve their delivery to brain. ${ }^{105,106}$ Surface charge modification is another approach that has been used to improve the targeted drug delivery of SLNs. Positively charged SLNs are found to deliver higher amounts of drugs to the brain than uncharged or negatively charged SLNs. Kuo and Chen prepared cationic SLNs loaded with the lipophilic protease inhibitor, saquinavir. ${ }^{107} \mathrm{~A}$ blend of the nonionic lipids Compritol ATO 888 and cacao butter were used as core lipids. Stearylamine and dioctadecyldimethyl ammonium bromide comprised the peripheral cationic lipids. Polysorbate 80 was used as an SLN emulsifier/stabilizer. However, this study did not include any in vitro or in vivo demonstration of their improved ability to deliver the drug to the target sites. The modification of surface charge to enhance drug delivery to the CNS must be applied with caution because positively charged SLNs and high amounts of negatively charged SLNs were shown to increase the cortical cerebrovascular volume of rats significantly in situ in brain perfusion experiments, indicating a compromise in the integrity of the BBB. ${ }^{108}$

\section{Liposomes}

Liposomes are lipid vesicles consisting of phospholipid bilayers. They have an aqueous core which can be used to encapsulate hydrophilic drugs while hydrophobic and amphiphilic drugs can be solubilized within the phospholipid bilayers. Liposomes are of three types, ie, small unilamellar vesicles, large unilamellar vesicles, and multilamellar vesicles. Liposomes in their native form are taken up by the reticuloendothelial system and are quickly cleared from the circulation. This property was exploited for the macrophage delivery of antiretrovirals. Phillips et al used a liposomal drug delivery system to deliver zidovudine to macrophages. ${ }^{109}$ Zidovudine, which is an amphiphilic compound, showed low entrapment and significant leakage from the liposomal vesicles over time, due to its tendency to partition between the aqueous core and the lipid bilayer. ${ }^{110}$ Jin et al studied the incorporation of the myristate prodrug of zidovudine in the liposomal formulation to target macrophages. ${ }^{27}$ The prodrug, being lipophilic, resulted in greater entrapment efficiency and a longer half-life, as demonstrated in vivo in rats.

Liposomes rendered elastic by the incorporation of an edge activator in the lipid bilayer were studied as transdermal delivery agents for antiretroviral drugs. ${ }^{11,112}$ Another approach used to improve the transdermal flux of liposomes is incorporation of ethanol into the liposomes to form ethosomes. Several in vitro and ex vivo studies were conducted by Jain et al incorporating antiretroviral drugs such as acyclovir, indinavir, zidovudine, and lamivudine into these modified liposomal systems. ${ }^{111-116}$ The in vitro studies and ex vivo studies using human cadaver and rodent skin models showed greater transdermal flux of antiretroviral drugs with the modified liposomes compared with conventional liposomes, ethanolic solutions, or hydroethanolic solutions.

Liposomes are quickly phagocytosed by macrophages upon entering the systemic circulation. To prolong their circulation time and improve their bioavailability to infected cells as well as macrophages, liposomal surfaces are coated with hydrophilic polymers, such as PEG. ${ }^{112,117}$ Approaches involving more specific targeting of liposomes were pursued to improve antiretroviral delivery further. Flasher et al used liposomes coupled to sCD4, a soluble form of the natural host ligand of gp120, to target HIV-infected cells. ${ }^{18,119}$ CD4-derived peptides were studied instead of sCD4 for the targeted delivery of liposomes due to the relative ease of 
their production and their nonimmunogenicity. ${ }^{120}$ Targeting moieties based on antibodies have been studied by several investigators for liposomal delivery of antiretrovirals. ${ }^{121-123}$ Clayton et al used a human monoclonal immunoglobulin G1 $\kappa$ (IgG1א) antibody, monoclonal antibody F105, that specifically binds to the viral gp120 as a targeting moiety on the pegylated liposomes. ${ }^{122}$ The antiretroviral protease inhibitor, PI1, a substituted benzimidazole sulfonamide encapsulated into these anti-HIV liposomes, was shown to be selectively delivered to HIV-infected cells. The inhibitory effect of the targeted PI1 on viral replication was greater than that of a comparable concentration of free or nontargeted drug.

Other studies evaluated the use of mannose and galactose as targeting moieties on liposomes. ${ }^{124-126}$ These moieties bind to lectin receptors present on the surface of cells of the mononuclear phagocyte system. Stavudine loaded into mannosylated and galactosylated liposomes exhibited greater cellular uptake by cells of the mononuclear phagocytic system and greater accumulation in organs of the reticuloendothelial system such as the liver, spleen, and lungs of Sprague Dawley rats compared with free drug solution or nonmodified liposomes. ${ }^{124,125}$

There are certain disadvantages to liposomes that limit their use in antiretroviral drug delivery. The hydrophilic drug-loading capacity of liposomes is very limited due to the small volume of the core (approximately $15 \mu \mathrm{L}$ ). ${ }^{20}$ Long-term physical and biologic stability is another challenging issue in the design of liposomal delivery systems which precludes their use for sustained drug delivery applications.

\section{Miscellaneous}

Cyclodextrins are a group of naturally occurring cyclic oligosaccharides composed of $(1,4)$-linked $\alpha$-D-glucopyranose units. Topologically, cyclodextrins form a torus with a hydrophobic interior and a hydrophilic exterior. This allows cyclodextrins to act as host molecules that form inclusion complexes with hydrophobic guest molecules. Thus, cyclodextrin complexes can be used to enhance the solubility of lipophilic antiretroviral drugs, as well as to protect them from external degradation. Several classes of cyclodextrins, including $\beta$-cyclodextrin, methyl- $\beta$-cyclodextrin, and 2 -hydroxypropyl- $\beta$-cyclodextrin, were studied for their ability to improve the solubility of the hydrophobic antiretroviral agents, efavirenz and UC781. ${ }^{127,128}$ Hydroxypropyl- $\beta$ cyclodextrin and methyl- $\beta$-cyclodextrin complexed to efavirenz showed faster in vitro dissolution rate profiles compared with free efavirenz. ${ }^{127}$ The in vitro inhibition demonstrated by a UC781:2-hydroxypropyl- $\beta$-cyclodextrin complex, as measured by $\mathrm{HIV}-1$ reverse transcriptase inhibitory assay, was found to be enhanced by more than 30 -fold when compared with noncomplexed UC781. ${ }^{128}$ In a separate study, Buchanan et al used hydroxylbutenyl- $\beta$ cyclodextrin to improve the bioavailability of saquinavir. ${ }^{129}$ The resulting complexes were found to have increased aqueous solubility and bioavailability in vivo as studied in Wistar-Hannover rats. The oral bioavailability of saquinavir was enhanced approximately nine-fold when administered as a complex compared with saquinavir mesylate.

Polymeric micelles composed of block copolymers have been utilized for improving aqueous solubility, membrane permeability, and site-specific delivery of several drug moieties. They have a vesicular or core shell structure similar to surfactant-based micelles, but self-associate at much lower concentrations, typically in the $0.1-1 \mu \mathrm{M}$ range compared with $0.1-1 \mathrm{mM}$ for surfactant-based micelles. ${ }^{130}$ The core of the micelles is usually derived from polymers, such as propylene oxide, aspartic acid, L-lysine, and caprolactone which constitute the hydrophobic block. The shell is composed of a hydrophilic block derived from polymers such as polyethyleneimine, polyvinylalcohol, and polyethyleneoxide. ${ }^{21,131}$ Depending on the polarity of the drug, it may be entrapped in the core, shell, or at the interface between the two. Block copolymers of poly(ethylene)oxide-polypropylene oxide, also known as Pluronics, are FDA-approved and are the most common block copolymers for the preparation of polymeric micelles used for drug delivery and targeting. Pluronics of intermediate length and hydrophobicity, such as P85, inhibit the efflux transporters, eg, adenosine triphosphate-binding cassette transporters that have been shown to reduce the oral bioavailability and CNS permeability of several classes of antiretroviral drugs. ${ }^{132}$ Coadministration of antiretroviral drugs such as zidovudine, nelfinavir, and lamivudine with P85 has been shown to enhance their permeability in vitro in bovine brain microvessel endothelial cells and macrophages. ${ }^{132,133}$ The enhancement of efficacy of antiretrovirals upon co-administration with P85 was demonstrated in vivo in a severe combined immunodeficiency mouse model of HIV-1 encephalitis. ${ }^{134}$ Ligands specific for the type of receptors present on the HIV-infected cells, such as galactose and lactose units, that specifically interact with lectin receptors on the HIV viral reservoir sites, such as $\mathrm{T}$ lymphocytes, macrophages, and dendritic cells, can be attached to the surface of the polymeric micelles to achieve drug targeting. ${ }^{21,135}$ However, the biological stability of the polymeric micelles remains an issue, limiting their use for sustained drug delivery applications. 
Nanoemulsions are kinetically stable transparent or translucent heterogeneous liquid dispersions which can exist as water-in-oil (w/o) or oil-in-water $(\mathrm{o} / \mathrm{w})$ forms. The internal phase liquid is reduced to droplets of $\leq 400 \mathrm{~nm} .^{15}$ Nanoemulsions are thermodynamically stable with very low surface tension, due to their small droplet size. ${ }^{136}$ The properties of the internal phase, including stability, are dependent on the composition of the surfactant present at the droplet interface. The choice of oil and surfactant will influence the in vitro as well as in vivo stability, transport, and release characteristics of the nanoemulsion formulation. Vyas et al used an o/w nanoemulsion to improve the oral bioavailability and brain delivery of saquinavir. ${ }^{137}$ The rate and extent of oral absorption followed by brain localization of saquinavir in BALB/c mice was found to be greater with saquinavir-loaded nanoemulsions than with an aqueous suspension of the drug.

Cell-based nanoformulations seem to be an efficient and promising drug delivery approach, especially to the viral sanctuary sites typically inaccessible to antiretroviral drugs. Dou et al explored a novel macrophage-based indinavir nanoformulation for the treatment of HIV infection. ${ }^{138-140}$ They postulated that macrophages, the principal reservoir sites responsible for dissemination of HIV, can enter into tissues and anatomic sites with limited access to antiretroviral drugs and, hence, they could be used as transporters for antiretroviral drugs themselves. In their study, indinavir-loaded lipid nanoparticles prepared with Lipoid E80 were incorporated into murine bone marrow-derived macrophages. These nanoparticulate drug-loaded macrophages were studied for their tissue distribution and disease outcomes with immunecompetent and HIV-1-infected humanized immune-deficient mice, respectively. ${ }^{138}$ Sustained drug levels far exceeding therapeutic concentrations accompanied by reduced viral load were achieved in serum and locally in HIV target tissues including lung, liver, and spleen in HIV-1 infected humanized immune-deficient mice for two weeks. ${ }^{138}$ In a later study in mice with HIV-1 encephalitis, indinavir nanoparticles were detected in the brain, especially in the regions with active astrogliosis, microgliosis, and neuronal loss, indicating the ability of these nanoformulations to overcome the BBB. ${ }^{140}$ The presence of these indinavir nanoparticles in the aforementioned brain subregions was associated with reduced HIV-1 replication. In separate studies, cell-based antiretroviral nanoformulations with human monocyte-derived macrophages were developed and studied for their properties in vitro. ${ }^{139,141}$ Initially, lipid nanoparticles of indinavir were packaged into the human macrophages. ${ }^{123}$ Later, a combination of indinavir-, ritonavir-, and efavirenz-loaded lipid nanoparticles were packaged into the human macrophages. ${ }^{141}$ The antiretroviral nanoparticles taken up into the cytoplasmic vesicles of the macrophages released the drugs for two weeks. Dose-dependent reduction of viral replication and HIV-1 p24 antigen were observed.

\section{Conclusion and future perspectives}

HIV infection has reached pandemic levels. Due to the complexities of both the HIV infection cycle and the targets for delivery of drugs intended to prevent or treat this disease, more efficient drug delivery systems are needed. Various forms of nanocarriers have been studied as a means to enhance the effective delivery of antiretroviral drugs for HIV prevention and therapy. Among these are nanoparticles (polymeric, inorganic, and solid lipid), liposomes, polymeric micelles, dendrimers, cyclodextrins, and cell-based nanoformulations. Such drug delivery systems have shown promise in various models ranging from in vitro to in vivo. It has been shown that the application of nanocarrier systems for delivery of antiretroviral drugs can achieve more efficient distribution, provide a mechanism to cross the BBB and other tissue or cell barriers to delivery, and provide a means to overcome innate barriers to delivery, such as mucus. Although a number of publications in this area have been presented within the scope of this review, work is still limited and must be expanded to elucidate fully the potential for application of nanocarrier delivery systems for the design of more efficient antiretroviral drug products.

As more information about HIV infection and lifecycle becomes available, nanocarriers with better surface modifiers for improved targeting and longer duration of action should become available. The majority of work done to date in the field of nanocarrier antiretroviral drug delivery systems involves the use of single antiretroviral agents. Given that it has been found that use of combinations of drugs can lead to more efficacious treatments and reduction of resistance profiles, studies applying nanocarriers to combined delivery strategies should be conducted. Further studies regarding the safety and efficacy profiles of the antiretroviral nanocarriers must be performed. Minimal information is currently available regarding the short- and long-term toxicity of nanocarriers. Finally, scale-up considerations for the manufacture of nanocarrier systems is another issue that needs to be addressed in order to make the nanocarrier therapeutic approach feasible.

\section{Disclosure}

The authors report no conflicts of interest in this work. 


\section{References}

1. World Health Organization. AIDS epidemic update, December 2009. Available at: http://data.unaids.org/pub/Report/2009/JC1700_Epi_ Update_2009_en.pdf. Accessed on May 12, 2010.

2. Stein ZA. HIV prevention: The need for methods women can use. $A m$ J Public Health. 1990;80(4):460-462.

3. Pauwels R, De Clercq E. Development of vaginal microbicides for the prevention of heterosexual transmission of HIV. J Acquir Immune Defic Syndr Hum Retrovirol. 1996;11(3):211-221.

4. McGowan I. Rectal microbicides: A new focus for HIV prevention. Sex Transm Infect. 2008;84(6):413-417.

5. Boggiano C, Littman DR. HIV's vagina travelogue. Immunity. 2007; 26(2):145-147.

6. Shattock RJ, Moore JP. Inhibiting sexual transmission of HIV-1 infection. Nat Rev Microbiol. 2003;1(1):25-34.

7. Hladik F, Hope TJ. HIV infection of the genital mucosa in women. Curr HIV/AIDS Rep. 2009;6(1):20-28.

8. Doms RW, Trono D. The plasma membrane as a combat zone in the HIV battlefield. Genes Dev. 2000;14(21):2677-2688.

9. Marechal V, Prevost MC, Petit C, Perret E, Heard JM, Schwartz O. Human immunodeficiency virus type 1 entry into macrophages mediated by macropinocytosis. J Virol. 2001;75(22):11166-11177.

10. Pauza CD, Price TM. Human immunodeficiency virus infection of $\mathrm{T}$ cells and monocytes proceeds via receptor-mediated endocytosis. J Cell Biol. 1988;107(3):959-968.

11. Fredericksen BL, Wei BL, Yao J, Luo T, Garcia JV. Inhibition of endosomal/lysosomal degradation increases the infectivity of human immunodeficiency virus. J Virol. 2002;76(22):11440-11446.

12. Daecke J, Fackler OT, Dittmar MT, Krausslich HG. Involvement of clathrin-mediated endocytosis in human immunodeficiency virus type 1 entry. J Virol. 2005;79(3):1581-1594.

13. Miyauchi K, Kim Y, Latinovic O, Morozov V, Melikyan GB. HIV enters cells via endocytosis and dynamin-dependent fusion with endosomes. Cell. 2009;137(3):433-444.

14. Holtgrave DR. Causes of the decline in AIDS deaths, United States, 1995-2002: Prevention, treatment or both? Int J STD AIDS. 2005; 16(12):777-781.

15. Vyas TK, Shah L, Amiji MM. Nanoparticulate drug carriers for delivery of HIV/AIDS therapy to viral reservoir sites. Expert Opin Drug Deliv. 2006;3(5):613-628.

16. Schrager LK, D'Souza MP. Cellular and anatomical reservoirs of HIV-1 in patients receiving potent antiretroviral combination therapy. JAMA. 1998;280(1):67-71.

17. Mallipeddi R, Rohan LC. Nanoparticle-based vaginal drug delivery systems for HIV prevention. Expert Opin Drug Deliv. 2010; 7(1):37-48.

18. Torchilin VP. Drug targeting. Eur J Pharm Sci. 2000;11(2): S81-S91.

19. Perera G, Greindl M, Palmberger TF, Bernkop-Schnurch A. Insulin-loaded poly (acrylic acid)-cysteine nanoparticles: Stability studies towards digestive enzymes of the intestine. Drug Deliv. 2009; 16(5):254-260.

20. Rao KS, Ghorpade A, Labhasetwar V. Targeting anti-HIV drugs to the CNS. Expert Opin Drug Deliv. 2009;6(8):771-784.

21. Sharma P, Garg S. Pure drug and polymer based nanotechnologies for the improved solubility, stability, bioavailability and targeting of anti-HIV drugs. Adv Drug Deliv Rev. 2010;62(4-5):491-502.

22. Ham AS, Cost MR, Sassi AB, Dezzutti CS, Rohan LC. Targeted delivery of PSC-RANTES for HIV-1 prevention using biodegradable nanoparticles. Pharm Res. 2009;26(3):502-511.

23. Takeuchi H, Yamamoto H, Kawashima Y. Mucoadhesive nanoparticulate systems for peptide drug delivery. Adv Drug Deliv Rev. 2001; 47(1):39-54.

24. Weber N, Ortega P, Clemente MI, et al. Characterization of carbosilane dendrimers as effective carriers of siRNA to HIV-infected lymphocytes. J Control Release. 2008;132(1):55-64.
25. Liu Y, Franzen S. Factors determining the efficacy of nuclear delivery of antisense oligonucleotides by gold nanoparticles. Bioconjug Chem. 2008;19(5):1009-1016.

26. Kuo Y-C, Chen H-H. Effect of nanoparticulate polybutylcyanoacrylate and methylmethacrylate-sulfopropylmethacrylate on the permeability of zidovudine and lamivudine across the in vitro blood-brain barrier. Int J Pharm. 2006;327(1-2):160-169.

27. Jin SX, Bi DZ, Wang J, Wang YZ, Hu HG, Deng YH. Pharmacokinetics and tissue distribution of zidovudine in rats following intravenous administration of zidovudine myristate loaded liposomes. Pharmazie. 2005;60(11):840-843.

28. Kim S, Kwon K, Kwon IC, Park K. Nanotechnology in drug delivery: Past, present and future. In: Villiers MM, Aramwit P, Kwon GS, editors. Nanotechnology in Drug Delivery. New York, NY: Springer; 2009.

29. Gref R, Minamitake Y, Peracchia MT, Trubetskoy V, Torchilin V, Langer R. Biodegradable long-circulating polymeric nanospheres. Science. 1994;263(5153):1600-1603.

30. Fu K, Harrell R, Zinski K, et al. A potential approach for decreasing the burst effect of protein from PLGA microspheres. J Pharm Sci. 2003;92(8):1582-1591.

31. Yoo HS, Oh JE, Lee KH, Park TG. Biodegradable nanoparticles containing doxorubicin-PLGA conjugate for sustained release. Pharm Res. 1999;16(7):1114-1118.

32. Langer R. Drug delivery and targeting. Nature. 1998;392(6679):5-10.

33. Schmidt C, Lamprecht A. Nanocarriers in drug delivery: Design, manufacture and physicochemical properties. In: Lamprecht A, editor. Nanotherapeutics - Drug Delivery Concepts in Nanoscience. Singapore: Pan Stanford; 2009.

34. das Neves J, Amiji MM, Bahia MF, Sarmento B. Nanotechnologybased systems for the treatment and prevention of HIV/AIDS. Adv Drug Deliv Rev. 2010;62(4-5):458-477.

35. Shahiwala A, Amiji MM. Nanotechnology-based delivery systems in HIV/AIDS therapy. Future HIV Therapy. 2007;1(1):49-59.

36. du Toit LC, Pillay V, Choonara YE. Nano-microbicides: Challenges in drug delivery, patient ethics and intellectual property in the war against HIV/AIDS. Adv Drug Deliv Rev. 2010;62(4-5):532-546.

37. Kingsley JD, Dou H, Morehead J, Rabinow B, Gendelman HE, Destache CJ. Nanotechnology: A focus on nanoparticles as a drug delivery system. J Neuroimmune Pharmacol. 2006;1(3):340-350.

38. Gunaseelan S, Gunaseelan K, Deshmukh M, Zhang X, Sinko PJ. Surface modifications of nanocarriers for effective intracellular delivery of anti-HIV drugs. Adv Drug Deliv Rev. 2010;62(4-5):518-531.

39. Wong HL, Chattopadhyay N, Wu XY, Bendayan R. Nanotechnology applications for improved delivery of antiretroviral drugs to the brain. Adv Drug Deliv Rev. 2010;62(4-5):503-517.

40. Dembri A, Montisci M-J, Gantier JC, Chacun H, Ponchel G. Targeting of 3'-azido 3'-deoxythymidine (AZT)-loaded poly(isohexylcyanoacrylate) nanospheres to the gastrointestinal mucosa and associated lymphoid tissues. Pharm Res. 2001;18(4):467-473.

41. Lobenberg R, Maas J, Kreuter J. Improved body distribution of 14Clabelled AZT bound to nanoparticles in rats determined by radioluminography. J Drug Target. 1998;5(3):171-179.

42. Mrsny RJ. Lessons from nature: "Pathogen-Mimetic" systems for mucosal nano-medicines. Adv Drug Deliv Rev. 2009;61(2): $172-192$.

43. Rekha MR, Sharma CP. Synthesis and evaluation of lauryl succinyl chitosan particles towards oral insulin delivery and absorption. J Control Release. 2009;135(2):144-151.

44. Thirawong N, Thongborisute J, Takeuchi H, Sriamornsak P. Improved intestinal absorption of calcitonin by mucoadhesive delivery of novel pectin-liposome nanocomplexes. J Control Release. 2008; 125(3):236-245.

45. Bernkop-Schnurch A. Mucoadhesive polymers: Strategies, achievements and future challenges. Adv Drug Deliv Rev. 2005;57(11): 1553-1555. 
46. Lai SK, Wang YY, Hanes J. Mucus-penetrating nanoparticles for drug and gene delivery to mucosal tissues. Adv Drug Deliv Rev. 2009; 61(2):158-171.

47. Lai SK, Wang YY, Wirtz D, Hanes J. Micro- and macrorheology of mucus. Adv Drug Deliv Rev. 2009;61(2):86-100.

48. Cone RA. Barrier properties of mucus. Adv Drug Deliv Rev. 2009; 61(2):75-85.

49. Lai SK, O'Hanlon DE, Harrold S, et al. Rapid transport of large polymeric nanoparticles in fresh undiluted human mucus. Proc Natl Acad Sci U S A. 2007;104(5):1482-1487.

50. Destache CJ, Belgum T, Christensen K, Shibata A, Sharma A, Dash A. Combination antiretroviral drugs in PLGA nanoparticle for HIV-1. BMC Infect Dis. 2009;9:198.

51. Shah L, Amiji M. Intracellular delivery of saquinavir in biodegradable polymeric nanoparticles for HIV/AIDS. Pharm Res. 2006; 23(11):2638-2645.

52. Mainardes RM, Gremiao MP, Brunetti IL, da Fonseca LM, Khalil NM. Zidovudine-loaded PLA and PLA-PEG blend nanoparticles: Influence of polymer type on phagocytic uptake by polymorphonuclear cells J Pharm Sci. 2009;98(1):257-267.

53. Kuo Y-C. Loading efficiency of stavudine on polybutylcyanoacrylate and methylmethacrylate-sulfopropylmethacrylate copolymer nanoparticles. Int J Pharm. 2005;290(1-2):161-172.

54. Kuo Y-C, Su F-L. Transport of stavudine, delavirdine, and saquinavir across the blood-brain barrier by polybutylcyanoacrylate, methylmethacrylate-sulfopropylmethacrylate, and solid lipid nanoparticles. Int J Pharm. 2007;340(1-2):143-152.

55. Kuo Y-C, Kuo C-Y. Electromagnetic interference in the permeability of saquinavir across the blood-brain barrier using nanoparticulate carriers. Int J Pharm. 2008;351(1-2):271-281.

56. Porcel E, Liehn S, Remita H, et al. Platinum nanoparticles: A promising material for future cancer therapy? Nanotechnology. 2010; 21(8):85103.

57. Jain KK. Nanodiagnostics: Application of nanotechnology in molecular diagnostics. Exp Rev Mol Diagn. 2003;3(2):153-161.

58. Wang J, Wang L, Sun Y, et al. Surface plasmon resonance biosensor based on Au nanoparticle in titania sol-gel membrane. Colloids Surf B Biointerfaces. 2010;75(2):520-525.

59. Zhou Y, Yu SH, Cui XP, Wang CY, Chen ZY. Formation of silver nanowires by a novel solid-liquid phase arc discharge method. Chem Mater. 1999;11(3):545-546.

60. Canizal G, Ascencio JA, Gardea-Torresday J, Yacamán MJ. Multiple twinned gold nanorods grown by bio-reduction techniques. J Nanoparticle Res. 2001;3(5):475-481.

61. Yu Chang S-S, Lee C-L, Wang CRC. Gold nanorods: Electrochemical synthesis and optical properties. J Phys Chem B. 1997; 101(34):6661-6664.

62. Sondi I, Salopek-Sondi B. Silver nanoparticles as antimicrobial agent: A case study on E. coli as a model for Gram-negative bacteria J Colloid Interface Sci. 2004;275(1):177-182.

63. Lu L, Sun RW, Chen R, et al. Silver nanoparticles inhibit hepatitis B virus replication. Antivir Ther. 2008;13(2):253-262.

64. Sun RW, Chen R, Chung NP, Ho CM, Lin CL, Che CM. Silver nanoparticles fabricated in Hepes buffer exhibit cytoprotective activities toward HIV-1 infected cells. Chem Commun (Camb). 2005; 28(40):5059-5061.

65. Wei D, Sun W, Qian W, Ye Y, Ma X. The synthesis of chitosan-based silver nanoparticles and their antibacterial activity. Carbohydr Res. 2009;344(17):2375-2382.

66. Baram-Pinto D, Shukla S, Perkas N, Gedanken A, Sarid R. Inhibition of Herpes simplex virus type 1 infection by silver nanoparticles capped with mercaptoethane sulfonate. Bioconjug Chem. 2009; 20(8):1497-1502.

67. Sun L, Singh AK, Vig K, Pillai SR, Singh SR. Silver nanoparticles inhibit replication of respiratory syncytial virus. J Biomed Nanotechnol. 2008;4:149-158.
68. Rogers J, Parkinson C, Choi Y, Speshock J, Hussain S. A preliminary assessment of silver nanoparticle inhibition of monkeypox virus plaque formation. Nanoscale Research Letters. 2008;3(4):129-133.

69. Elechiguerra JL, Burt JL, Morones JR, et al. Interaction of silver nanoparticles with HIV-1. J Nanobiotechnology. 2005;3:6.

70. Lara HH, Ayala-Nunez NV, Ixtepan-Turrent L, Rodriguez-Padilla C. Mode of antiviral action of silver nanoparticles against HIV-1. J Nanobiotechnology. 2010;8:1.

71. Bowman M-C, Ballard TE, Ackerson CJ, Feldheim DL, Margolis DM, Melander C. Inhibition of HIV fusion with multivalent gold nanoparticles. J Am Chem Soc. 2008;130(22):6896-6897.

72. Braydich-Stolle L, Hussain S, Schlager JJ, Hofmann MC. In vitro cytotoxicity of nanoparticles in mammalian germline stem cells. Toxicol Sci. 2005;88(2):412-419.

73. AshaRani PV, Low Kah Mun G, Hande MP, Valiyaveettil S. Cytotoxicity and genotoxicity of silver nanoparticles in human cells. ACS Nano. 2009;3(2):279-290.

74. Kawata K, Osawa M, Okabe S. In vitro toxicity of silver nanoparticles at noncytotoxic doses to HepG2 human hepatoma cells. Environ Sci Technol. 2009;43(15):6046-6051.

75. Hussain SM, Hess KL, Gearhart JM, Geiss KT, Schlager JJ. In vitro toxicity of nanoparticles in BRL 3A rat liver cells. Toxicol In Vitro. 2005;19(7):975-983.

76. Kim YS, Kim JS, Cho HS, et al. Twenty-eight-day oral toxicity, genotoxicity, and gender-related tissue distribution of silver nanoparticles in Sprague-Dawley rats. Inhal Toxicol. 2008;20(6):575-583.

77. Zhao J, Bowman L, Zhang X, et al. Titanium dioxide ( $\mathrm{TiO} 2$ ) nanoparticles induce JB6 cell apoptosis through activation of the Caspase-8/ bid and mitochondrial pathways. J Toxicol Environ Health, Part A: Current Issues. 2009;72(19):1141-1149.

78. Goodman CM, McCusker CD, Yilmaz T, Rotello VM. Toxicity of gold nanoparticles functionalized with cationic and anionic side chains. Bioconjug Chem. 2004;15(4):897-900.

79. Svenson S, Tomalia DA. Dendrimers in biomedical applications reflections on the field. Adv Drug Deliv Rev. 2005; 57(15):2106-2129.

80. Bosman AW, Janssen HM, Meijer EW. About dendrimers: Structure, physical properties, and applications. Chem Rev. 1999; 99(7):1665-1688.

81. Gajbhiye V, Palanirajan VK, Tekade RK, Jain NK. Dendrimers as therapeutic agents: A systematic review. J Pharm Pharmacol. 2009; 61(8):989-1003.

82. Oka H, Onaga T, Koyama T, et al. Syntheses and biological evaluations of carbosilane dendrimers uniformly functionalized with sialyl [alpha] $(2->3)$ lactose moieties as inhibitors for human influenza viruses. Bioorg Med Chem. 2009;17(15):5465-5475.

83. Barnard DL, Sidwell RW, Gage TL, Okleberry KM, Matthews B, Holan G. Anti-respiratory syncytial virus activity of dendrimer polyanions. Antiviral Res. 1997;34(2):88-88(1).

84. Macri RV, Karlovská J, Doncel GF, et al. Comparing anti-HIV, antibacterial, antifungal, micellar, and cytotoxic properties of tricarboxylato dendritic amphiphiles. Bioorg Med Chem. 2009;17(8):3162-3168.

85. Dutta T, Garg M, Jain NK. Targeting of efavirenz loaded tuftsin conjugated poly(propyleneimine) dendrimers to HIV infected macrophages in vitro. Eur J Pharm Sci. 2008;34(2-3):181-189.

86. Dutta T, Jain NK. Targeting potential and anti-HIV activity of lamivudine loaded mannosylated poly (propyleneimine) dendrimer. Biochim Biophys Acta. 2007;1770(4):681-686.

87. Harouse JM, Kunsch C, Hartle HT, et al. CD4-independent infection of human neural cells by human immunodeficiency virus type 1. JVirol. 1989;63(6):2527-2533.

88. Harouse JM, Bhat S, Spitalnik SL, et al. Inhibition of entry of HIV-1 in neural cell lines by antibodies against galactosyl ceramide. Science. 1991;253(5017):320-323.

89. Moulard M, Lortat-Jacob H, Mondor I, et al. Selective interactions of polyanions with basic surfaces on human immunodeficiency virus type 1 gp120. J Virol. 2000;74(4):1948-1960. 
90. McCarthy TD, Karellas P, Henderson SA, et al. Dendrimers as drugs: Discovery and preclinical and clinical development of dendrimer-based microbicides for HIV and STI prevention. Mol Pharm. 2005;2(4):312-318.

91. Jiang Y-H, Emau P, Cairns JS, et al. SPL7013 gel as a topical microbicide for prevention of vaginal transmission of SHIV89.6P in macaques. AIDS Res Hum Retroviruses. 2005;21(3):207-213.

92. Rupp R, Rosenthal SL, Stanberry LR. VivaGel (SPL7013 Gel): A candidate dendrimer - microbicide for the prevention of HIV and HSV infection. Int J Nanomedicine. 2007;2(4):561-566.

93. Patton DL, Cosgrove Sweeney YT, McCarthy TD, Hillier SL. Preclinical safety and efficacy assessments of dendrimer-based (SPL7013) microbicide gel formulations in a nonhuman primate model. Antimicrob Agents Chemother. 2006;50(5):1696-1700.

94. Choi Y, Yoshida T, Mimura T, et al. Synthesis of sulfated octadecyl ribo-oligosaccharides with potent anti-AIDS virus activity by ringopening polymerization of a 1,4-anhydroribose derivative. Carbohydr Res. 1996;282(1):113-123.

95. Röy R, Zanini D, Meunier SJ, Romanowska A. Solid-phase synthesis of dendritic sialoside inhibitors of influenza A virus haemagglutinin. J Chem Soc, Chem Commun. 1993;24:1869-1872.

96. Han S, Yoshida D, Kanamoto T, Nakashima H, Uryu T, Yoshida T. Sulfated oligosaccharide cluster with polylysine core scaffold as a new anti-HIV dendrimer. Carbohydr Polym. 2010; 80(4):1111-1115.

97. Blanzat M, Turrin CO, Perez E, Rico-Lattes I, Caminade AM, Majoral JP. Phosphorus-containing dendrimers bearing galactosylceramide analogs: Self-assembly properties. Chem Commun (Camb). 2002;17:1864-1865.

98. Blanzat M, Turrin CO, Aubertin AM, et al. Dendritic catanionic assemblies: In vitro anti-HIV activity of phosphorus-containing dendrimers bearing galbeta1cer analogues. Chembiochem. 2005; 6(12):2207-2213.

99. Pérez-Anes A, Stefaniu C, Moog C, et al. Multivalent catanionic GalCer analogs derived from first generation dendrimeric phosphonic acids. Bioorg Med Chem. 2010;18(1):242-248.

100. Heiati H, Tawashi R, Shivers RR, Phillips NC. Solid lipid nanoparticles as drug carriers. I. Incorporation and retention of the lipophilic prodrug 3'-azido-3'-deoxythymidine palmitate. Int J Pharm. 1997;146(1):123-131.

101. Heiati H, Tawashi R, Phillips NC. Solid lipid nanoparticles as drug carriers: II. Plasma stability and biodistribution of solid lipid nanoparticles containing the lipophilic prodrug 3'-azido-3'-deoxythymidine palmitate in mice. Int J Pharm. 1998;174(1-2):71-80.

102. Yang S, Zhu J, Lu Y, Liang B, Yang C. Body distribution of camptothecin solid lipid nanoparticles after oral administration. Pharm Res. 1999;16(5):751-757.

103. Zara GP, Cavalli R, FundarÒ A, Bargoni A, Caputo O, Gasco MR. Pharmacokinetics of doxorubicin incorporated in solid lipid nanospheres (SLN). Pharmacol Res. 1999;40(3):281-286.

104. Chattopadhyay N, Zastre J, Wong HL, Wu XY, Bendayan R. Solid lipid nanoparticles enhance the delivery of the HIV protease inhibitor, atazanavir, by a human brain endothelial cell line. Pharm Res. 2008;25(10):2262-2271.

105. Zara GP, Cavalli R, Bargoni A, Fundaro A, Vighetto D, Gasco MR. Intravenous administration to rabbits of non-stealth and stealth doxorubicin-loaded solid lipid nanoparticles at increasing concentrations of stealth agent: Pharmacokinetics and distribution of doxorubicin in brain and other tissues. J Drug Target. 2002;10(4):327-335.

106. Fundarò A, Cavalli R, Bargoni A, Vighetto D, Zara GP, Gasco MR. Non-stealth and stealth solid lipid nanoparticles (SLN) carrying doxorubicin: Pharmacokinetics and tissue distribution after i.v. administration to rats. Pharmacol Res. 2000;42(4):337-343.

107. Kuo Y-C, Chen H-H. Entrapment and release of saquinavir using novel cationic solid lipid nanoparticles. Int J Pharm. 2009;365(1-2): 206-213.
108. Lockman PR, Koziara JM, Mumper RJ, Allen DD. Nanoparticle surface charges alter blood-brain barrier integrity and permeability. J Drug Target. 2004;12(9-10):635-641.

109. Phillips NC, Skamene E, Tsoukas C. Liposomal encapsulation of 3'-azido-3'-deoxythymidine (AZT) results in decreased bone marrow toxicity and enhanced activity against murine AIDS-induced immunosuppression. J Acquir Immune Defic Syndr. 1991;4(10):959-966.

110. Phillips NC, Tsoukas C. Liposomal encapsulation of azidothymidine results in decreased hematopoietic toxicity and enhanced activity against murine acquired immunodeficiency syndrome. Blood. 1992; 79(5):1137-1143.

111. Jain S, Tiwary AK, Jain NK. Sustained and targeted delivery of an anti-HIV agent using elastic liposomal formulation: Mechanism of action. Curr Drug Deliv. 2006;3(2):157-166.

112. Jain S, Tiwary AK, Jain NK. PEGylated elastic liposomal formulation for lymphatic targeting of zidovudine. Curr Drug Deliv. 2008;5(4):275-281.

113. Gupta U, Jain NK. Non-polymeric nano-carriers in HIV/AIDS drug delivery and targeting. Adv Drug Deliv Rev. 2010;62(4-5):478-490.

114. Jain S, Umamaheshwari R, Bhadra D, Jain N. Ethosomes: A novel vesicular carries for enhanced transdermal delivery of an anti HIV agent. Ind J Pharm Sci. 2004;66(1):72-81.

115. Jain S, Tiwary A, Sapra B, Jain N. Formulation and evaluation of ethosomes for transdermal delivery of lamivudine. AAPS PharmSciTech. 2007;8(4):249-257.

116. Dubey V, Mishra D, Nahar M, Jain V, Jain NK. Enhanced transdermal delivery of an anti-HIV agent via ethanolic liposomes. Nanomedicine. 2010 Jan 20. [Epup ahead of print].

117. Pretzer E, Flasher D, Duzgunes N. Inhibition of human immunodeficiency virus type-1 replication in macrophages and $\mathrm{H} 9$ cells by free or liposome-encapsulated L-689,502, an inhibitor of the viral protease. Antiviral Res. 1997;34(1):1-15.

118. Flasher D, Konopka K, Chamow SM, et al. Liposome targeting to human immunodeficiency virus type 1 -infected cells via recombinant soluble CD4 and CD4 immunoadhesin (CD4-IgG). Biochim Biophys Acta. 1994;1194(1):185-196.

119. Duzgunes N, Pretzer E, Simoes S, et al. Liposome-mediated delivery of antiviral agents to human immunodeficiency virus-infected cells. Mol Membr Biol. 1999;16(1):111-118.

120. Slepushkin VA, Salem II, Andreev SM, Dazin P, Düzgünes N. Targeting of liposomes to HIV-1-infected cells by peptides derived from the CD4 receptor. Biochem Biophys Res Comm. 1996;227(3): 827-833.

121. Gagne JF, Desormeaux A, Perron S, Tremblay MJ, Bergeron MG. Targeted delivery of indinavir to HIV-1 primary reservoirs with immunoliposomes. Biochim Biophys Acta. 2002;1558(2):198-210.

122. Clayton R, Ohagen A, Nicol F, et al. Sustained and specific in vitro inhibition of HIV-1 replication by a protease inhibitor encapsulated in gp120-targeted liposomes. Antiviral Res. 2009;84(2):142-149.

123. Bestman-Smith J, Gourde P, Désormeaux A, Tremblay MJ, Bergeron MG. Sterically stabilized liposomes bearing anti-HLA-DR antibodies for targeting the primary cellular reservoirs of HIV-1. Biochim Biophys Acta. 2000;1468(1-2):161-174.

124. Garg M, Asthana A, Agashe HB, Agrawal GP, Jain NK. Stavudineloaded mannosylated liposomes: In-vitro anti-HIV-I activity, tissue distribution and pharmacokinetics. $J$ Pharm Pharmacol. 2006;58:605-616.

125. Garg M, Garg BR, Jain S, et al. Radiolabeling, pharmacoscintigraphic evaluation and antiretroviral efficacy of stavudine loaded $99 \mathrm{mTc}$ labeled galactosylated liposomes. Eur J Pharm Sci. 2008;33(3):271-281.

126. Garg M, Jain NK. Reduced hematopoietic toxicity, enhanced cellular uptake and altered pharmacokinetics of azidothymidine loaded galactosylated liposomes. J Drug Target. 2006;14(1):1-11.

127. Sathigari S, Chadha G, Lee YH, et al. Physicochemical characterization of efavirenz-cyclodextrin inclusion complexes. AAPS PharmSciTech. 2009;10(1):81-87. 
128. Yang H, Parniak MA, Isaacs CE, Hillier SL, Rohan LC. Characterization of cyclodextrin inclusion complexes of the antiHIV non-nucleoside reverse transcriptase inhibitor UC781. AAPS J. 2008;10(4):606-613.

129. Buchanan CM, Buchanan NL, Edgar KJ, et al. Pharmacokinetics of saquinavir after intravenous and oral dosing of saquinavir: hydroxybutenyl- $\hat{\mathrm{I}}^{2}$-cyclodextrin formulations. Biomacromolecules. 2007;9(1):305-313.

130. Adams ML, Lavasanifar A, Kwon GS. Amphiphilic block copolymers for drug delivery. J Pharm Sci. 2003;92(7):1343-1355.

131. Torchilin VP. Micellar nanocarriers: Pharmaceutical perspectives. Pharm Res. 2007;24(1):1-16.

132. Shaik N, Pan G, Elmquist WF. Interactions of pluronic block copolymers on P-gp efflux activity: Experience with HIV-1 protease inhibitors. J Pharm Sci. 2008;97(12):5421-5433.

133. Batrakova EV, Li S, Miller DW, Kabanov AV. Pluronic P85 increases permeability of a broad spectrum of drugs in polarized BBMEC and Caco-2 cell monolayers. Pharm Res. 1999;16(9):1366-1372.

134. Spitzenberger TJ, Heilman D, Diekmann C, et al. Novel delivery system enhances efficacy of antiretroviral therapy in animal model for HIV-1 encephalitis. J Cereb Blood Flow Metab. 2007;27(5):1033-1042.
135. NagasakiY, Yasugi K, Yamamoto Y, Harada A, Kataoka K. Sugar-installed block copolymer micelles: Their preparation and specific interaction with lectin molecules. Biomacromolecules. 2001;2(4):1067-1070.

136. Sarker DK. Engineering of nanoemulsions for drug delivery. Curr Drug Deliv. 2005;2(4):297-310.

137. Vyas TK, Shahiwala A, Amiji MM. Improved oral bioavailability and brain transport of saquinavir upon administration in novel nanoemulsion formulations. Int J Pharm. 2008;347(1-2):93-101.

138. Dou H, Destache CJ, Morehead JR, et al. Development of a macrophage-based nanoparticle platform for antiretroviral drug delivery. Blood. 2006;108(8):2827-2835.

139. Dou H, Morehead J, Destache CJ, et al. Laboratory investigations for the morphologic, pharmacokinetic, and anti-retroviral properties of indinavir nanoparticles in human monocyte-derived macrophages. Virology. 2007;358(1):148-158.

140. Dou H, Grotepas CB, McMillan JM, et al. Macrophage delivery of nanoformulated antiretroviral drug to the brain in a murine model of neuroAIDS. J Immunol. 2009;183(1):661-669.

141. Nowacek AS, Miller RL, McMillan J, et al. NanoART synthesis, characterization, uptake, release and toxicology for human monocytemacrophage drug delivery. Nanomedicine (Lond). 2009;4(8):903-917.
International Journal of Nanomedicine

\section{Publish your work in this journal}

The International Journal of Nanomedicine is an international, peerreviewed journal focusing on the application of nanotechnology in diagnostics, therapeutics, and drug delivery systems throughout the biomedical field. This journal is indexed on PubMed Central, MedLine, CAS, SciSearch $®$, Current Contents ${ }^{\circledR} /$ Clinical Medicine,

\section{Dovepress}

Journal Citation Reports/Science Edition, EMBase, Scopus and the Elsevier Bibliographic databases. The manuscript management system is completely online and includes a very quick and fair peer-review system, which is all easy to use. Visit http://www.dovepress.com/ testimonials.php to read real quotes from published authors. 